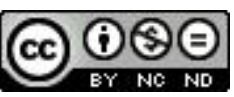

$\overline{\text { ARTIGOS }}$

\title{
A História da Derivada de Mariana: uma experiência didática
}

\section{The History of Mariana's Derivative: an experiment in didactics}

\author{
Roberto Ribeiro Baldino" \\ Aline Schröpfer Fracalossi**
}

\begin{abstract}
Resumo
Neste artigo introduzimos o conceito de derivada como quociente de infinitésimos através de uma história para crianças e adultos. Incluímos o relato da compreensão, da história e do conceito, demonstradas por duas meninas, uma de 10, outra de 12 anos. Segue uma breve apologia em favor do uso dos infinitésimos no ensino de cálculo e com a descrição do contexto de uma sala de aula de cálculo para calouros, onde essa história foi aplicada como ficha de trabalho. Lançamos um repto aos professor de cálculo e autores de livros textos: produzam algo igualmente acessível para apresentar o conceito de derivada pela via dos limites.
\end{abstract}

Palavras-chave: Infinitésimo. Derivada. Diferencial. Limite. Zoom.

\begin{abstract}
In this paper we tell a story for children and adults designed to introduce the concept of derivative as a quotient of infinitesimals. We report on the understanding of 11 and 12-

\footnotetext{
* Doutor em Matemática, Instituto de Matemática Pura e Aplicada (IMPA). Professor do Curso de Engenharia em Sistemas Digitais da Universidade Estadual do Rio Grande do Sul (UERGS), Guaíba, RS, Brasil. Endereço para Correspondência: Cx. P. 133, CEP: 92500-000, Guaíba, RS, Brasil. Email: rrbaldino@terra.com.br.

** Aluna do segundo semestre do Curso de Engenharia em Sistemas Digitais da Universidade Estadual do Rio Grande do Sul (UERGS), Guaíba, RS, Brasil. Endereço para Correspondência: Rua 26, bloco 283, apartamento n 06, Cohab, CEP: 92500-000, Guaíba, Rio Grande do Sul, Brasil. E-mail: alinesfracalossi@hotmail.com.
} 
years old girls about the story and the concept. A brief justification for the use of infinitesimals in the teaching of calculus follows, as well as a description of the context of a freshmen calculus course classroom where this story was used as a worksheet. We challenge the calculus teachers and textbook authors to produce something equally accessible for the introduction of the concept of derivative via the theory of limits.

Keywords: Infinitesimal. Derivative. Differential. Limit. Zoom.

\section{A História da derivada}

Era uma vez uma função que se chamava Mariana. Como toda função que se preza, Mariana se apresentava por seu gráfico, aqui, nesta primeira figura; Mariana assinava $\mathrm{f}(\mathrm{x})$. (efe de xis).

O gráfico de Mariana tinha muitos pontos, todos iguais, cada um ocupando sua posição.

Mas tinha um ponto, o Ponto $\mathrm{P}$, muito exibido que queria ser diferente.

Tanto incomodou e pediu para ser diferente que Mariana lhe disse:

Está bem, vou te dar uma reta tangente minha, passando por ti e só por ti.

O ponto ficou muito contente, mas quando Mariana lhe perguntou se ele tinha gostado, ele respondeu que não via a tal reta tangente.

Vocês sabem por que o ponto não via a reta tangente?

É que o país do ponto é muito pequeno... Vocês querem conhecer o país do ponto?

Para viajar ao país do ponto nós precisamos olhar o ponto bem de pertinho... Temos de usar um microscópio muito, muito forte.

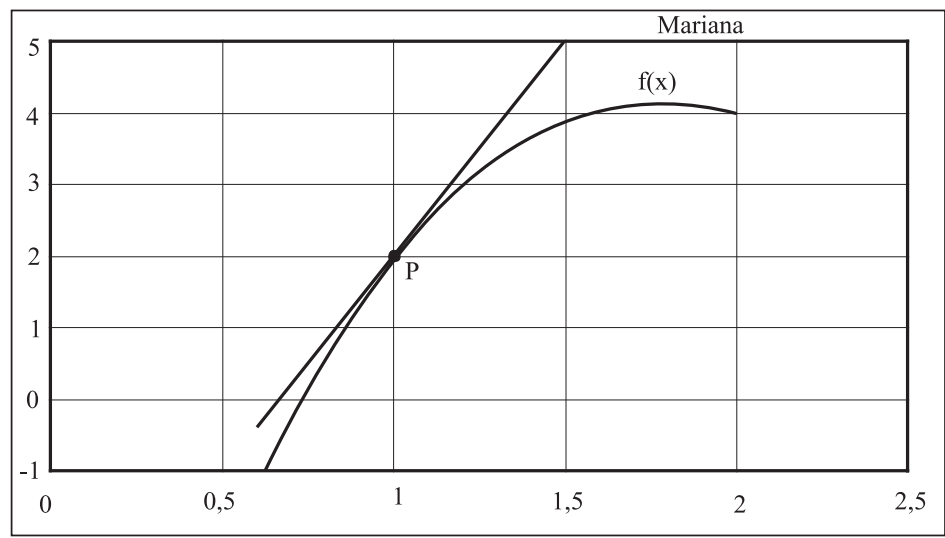

Figura 1 - O ponto ganha uma reta tangente. 
Então, ampliamos o mundo do ponto na segunda figura.

O mundo do ponto chama-se Mônada.

Na Mônada mora só um ponto; não pode ter dois, para não brigarem.

Na Mônada moram, também, muitas figuras que obedecem ao ponto: quadrados, triângulos, círculos...

Todos os habitantes da Mônada são muito, muito pequenos, tão pequenos que nem se pode medi-los. Eles são chamados infinitésimos.

Foi então, que Mariana explicou ao Ponto:

Olhe bem, você está, sim, vendo a reta tangente. É que na sua Mônada a reta tangente fica bem, bem grudadinha a mim. Por isso parece que sou eu.

O ponto focou satisfeito: olhava para Mariana e via a reta tangente; olhava para a reta tangente e via Mariana.

Porém, na Mônada do Ponto moravam dois infinitésimos muito travessos, o $d x$ e o $d f$.

$\mathrm{O} d x$ e o $d f$ viviam brigando, porque o $d x$ só queria andar pra frente e pra trás e o $d f$ só queria andar pra cima e pra baixo. Cada um queria que o outro andasse como ele; os dois eram teimosos.

Para que eles parassem de brigar, o Ponto chamou os dois e disse:

Olhem, vocês só podem andar começando aqui, onde eu estou. Cada vez que o $d x$ andar, $d f$ tem que começar onde ele parou e andar até a reta tangente. Cada vez que o $d f$ andar, o $d x$ tem que começar onde o $d f$ parou e andar até a reta tangente. Podem andar para lá e para cá, para cima e para baixo, mas obedeçam.

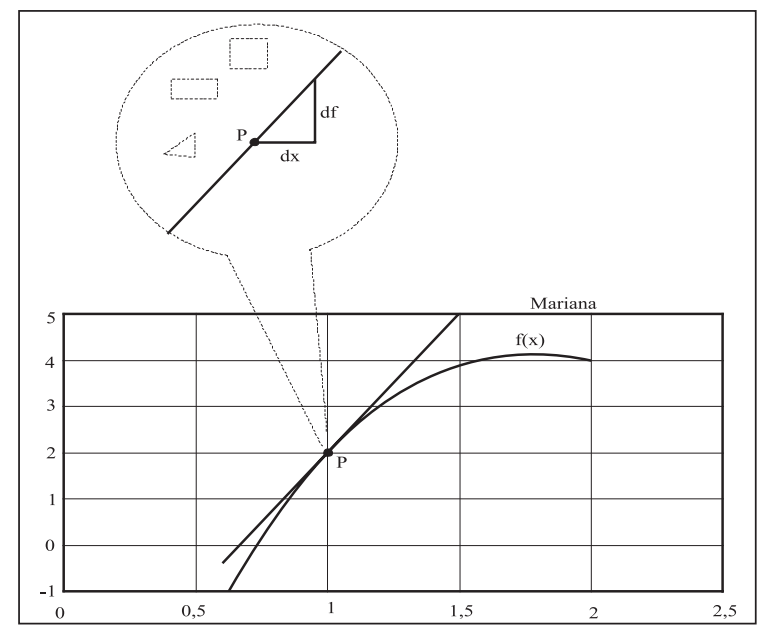

Figura 2 - Como andavam o $d x$ e o $d f$. 
Como os infinitésimos todos obedeciam ao Ponto, o $d x$ e o $d f$ pararam de brigar e se divertiram muito. Um caminhava, o outro continuava... Um se espichava mais, o outro tinha que se espichar também; o outro se encolhia, e este tinha que se encolher também; quando o $d x$ andava para trás, o $d f$ tinha de andar para baixo.Descobriram até de quantas maneiras podiam fazer isso.

Mas logo começaram a discutir: queriam saber quem andava mais.

Não podiam medir, porque a Mônada era tão pequena que nada se podia medir; eram todos infinitésimos.

Então, o $d x$ e o $d f$ foram perguntar ao Ponto como poderiam saber quem andava mais.

O Ponto pensou, pensou e teve uma ideia:
Já sei, disse. Vamos dividir o df pelo dx e vamos fazer a conta $\frac{d f}{d x}$. Se der mais que um, por exemplo, se o resultado da divisão for dois, é porque o df caminha duas vezes mais que o $d x$; se o resultado for menor que um, por exemplo, se for 0,5, é porque o dx caminha duas vezes mais que o $d f$.

Todos ficaram muito contentes com a ideia que teve o ponto, mas logo surgiu uma dificuldade: como poderiam dividir $d f$ por $d x$ se não sabiam quanto cada um media? Eram todos infinitésimos, não se podia medi-los.

Perguntaram a todas as figuras da Mônada, mas ninguém tinha a resposta.

Vocês têm alguma ideia?

Não tiveram outro jeito senão perguntar à Mariana, que falou assim.

É muito fácil, vocês não podem medir porque dentro da Mônada não tem medida, mas eu posso. É só vocês se espicharem bem, para que eu possa vê-los.

Então, o $d f$ e o $d x$ se espicharam, se espicharam até que começaram a aparecer fora da Mônada.

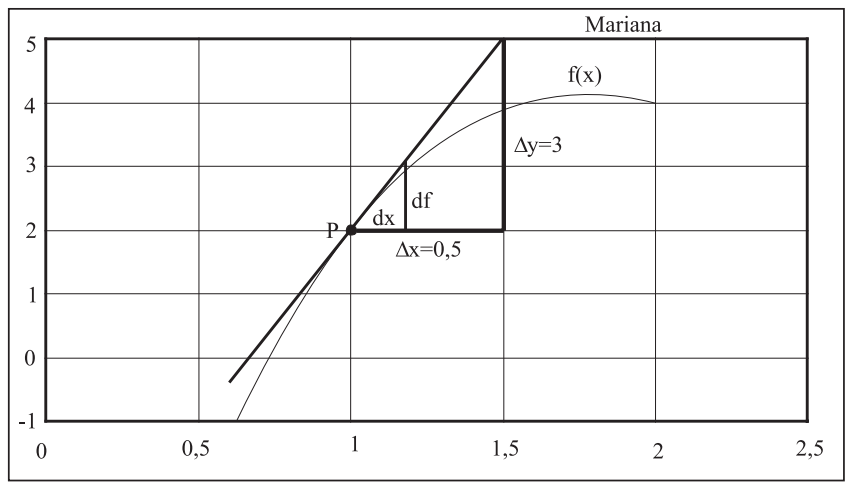

Figura 3-O $d x$ e o $d f$ se espicharam... 
Mariana concluiu:

O resultado da conta $\frac{d f}{d x}$ que vocês querem calcular é igual ao resultado desta conta aqui.

Mariana tomou $\Delta y$ e $\Delta x$ e mediu: $\Delta y=3 \Delta x=0,5$. Então, concluiu ela:

Vejam: $d f$ caminha seis vezes mais que $d x$, porque, ó: $\frac{d f}{d y}=\frac{\Delta y}{\Delta x}=\frac{3}{0,5}=6$.

Todos os habitantes da Mônada ficaram muito contentes, porque $d f$ e $d x$ ficaram muito amigos e pararam de brigar .

Logo a notícia se espalhou para as mônadas dos outros pontos do gráfico de Mariana.

Em cada uma morava um $d x$ e um $d f$. Todos queriam saber qual caminhava mais.

Mariana deu a cada ponto sua reta tangente e calculou $\frac{d f}{d x}$ para cada uma.

Para não se atrapalhar ela organizou uma tabela, cada ponto com o seu $\frac{d f}{d x}$ ao lado.

Depois, para mostrar o que tinham feito às outras funções da sua escola, Mariana desenhou um gráfico para representar essa tabela.

Foi então, que ela descobriu que tinha inventado outra função. Mariana chamou essa nova função de derivada de Mariana e representou por Mariana' (Mariana Linha) e assinou $f^{\prime}(x)$ (efe linha de xis).

E todos os infinitésimos

de todas as mônadas

de todos os pontos

de todas as funções

de todas as crianças

de todas as escolas

viveram em paz por muitos e muitos anos. 
Desenhe o gráfico que Mariana obteve para a Derivada de Mariana:

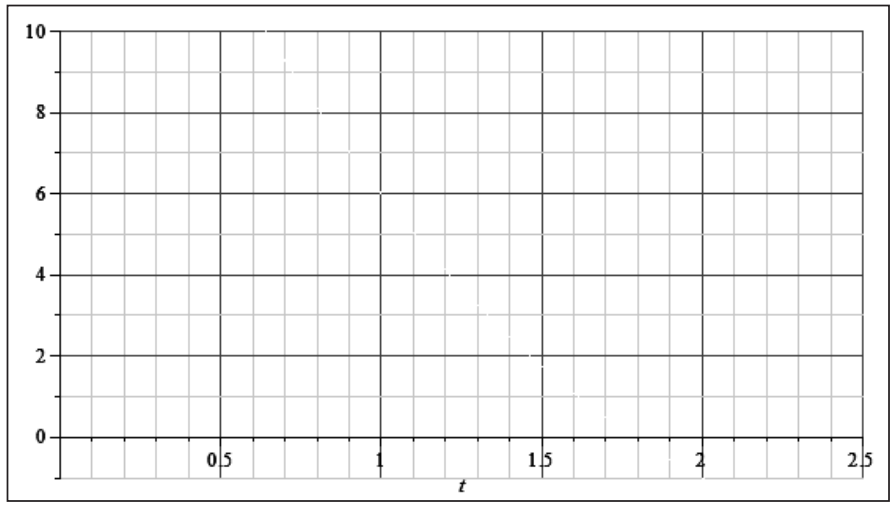

Figura 4 - Desenhe o gráfico da derivada.

\section{Relato de Aline Fracalossi sobre uma menina de 12 anos}

No Dia 10 de novembro de 2010, por volta de dezenove horas, contei a história da Derivada de Mariana para a filha de 12 anos de uma amiga, por MSN. Ela mora em uma cidade do interior do RS, eu, em Guaíba, na Grande Porto Alegre. A conversa por MSN foi assim:

Aline: Inópia ${ }^{1}$, você quer aprender uma história muito legal?

Inópia: Sim, qual história?

Aline: A história da Derivada de Mariana.

Inópia: O que é a história da Derivada de Mariana?

Aline: É uma história muito interessante. Eu te conto e daí você vai entender o que é essa história, é muito fácil e eu tenho certeza que você vai gostar. Eu aprendi essa história aqui na faculdade com o meu professor de matemática e geometria.

Então, eu relatei a história da Derivada de Mariana para ela, exatamente como aparece acima. Desenhei os gráficos com o auxílio do paint e enviei pra ela. Ela leu, pensou durante mais ou menos meia hora. Como tinha algumas dúvidas, ela me ligou:

Inópia: Oi Aline, por que o nome da história é Derivada de Mariana?

Aline: Porque meu professor contou essa história para uma menina de 10 anos chamada Mariana. Se você entender essa história, eu dou o nome pra história de Derivada de Inópia, mas para isso você tem que me contar a história.

\footnotetext{
${ }^{1}$ Nome fictício.
} 
Inópia: Sério que você pode dar o meu nome pra história?

Aline: Claro, Inópia.

Inópia: O microscópio é igual ao zoom que a gente dá nas fotos? E infinitésimo é o nome das pessoas que moram lá no país do ponto?

Aline: Isso mesmo. E elas são chamadas de infinitésimos, porque são muito pequenas, a gente só as vê se der zoom.

Inópia: O que significa Mariana Linha?

Aline: Mariana Linha é o nome da função que ela descobriu. Ela não podia representar a nova função como Mariana também, porque as duas não eram iguais. Por isso, ela chamou de Mariana Linha, mas ela poderia ter chamado de Mariana Um, por exemplo.

Nisso, ouvi minha amiga falar com ela; dizia que Inópia não devia dar ouvidos ao que eu estava falando; que era um absurdo eu tentar ensinar algo que eu aprendi na faculdade para uma criança de doze anos; que ela devia se preocupar com o que os professores dela estavam ensinando no colégio; que eu não era professora, muito menos mãe dela pra ensinar alguma coisa. Mas eu sabia que isso era só implicância da parte de minha amiga, pois ela nunca aprovou as minhas intenções de ajudar Inópia na escola ou no que quer que fosse. Para minha amiga, só ela tem capacidade para ensinar algo.

Por um momento, eu pensei que Inópia ia acatar o que a mãe dela dizia, e ia desistir da história, mas sua resposta me surpreendeu. Ela disse para minha amiga que o que eu estava ensinando pra ela era muito legal, e que ela queria aprender aquela história. E que, se ela entendesse a história da Derivada de Mariana, esta ia passar a se chamar história da Derivada de Inópia. Tenho certeza que minha amiga, ao ouvir isso, também se surpreendeu.

Mais tarde, Inópia voltou a falar comigo, disse-me que tinha destacado essas partes da história. E me relatou a história assim:

Aline, eu tenho um gráfico e ele tem vários pontos iguais, mas um desses pontos, o P que é muito exibido e queria ser diferente, por isso Mariana deu pra ele uma reta que passava só por ele.

Pra podermos ver esse ponto temos que dar um zoom em cima do ponto. Lá moram duas pessoas que viviam brigando, o dx e o df. O dx só queria andar pra frente e pra trás e o df pra cima e pra baixo. Para acabar com essas brigas, o ponto disse pra eles que cada vez que um andar, o outro tem que começar de onde este parou até a reta. Depois, eles quiseram saber quem andava mais.

Para descobrir quem andava mais, eles pediram ajuda para Mariana, 
porque eles eram muito, muito pequenos. Mariana disse que era pra eles se espicharem bem para que ela pudesse vê-los. Então, Mariana pode dividir o df pelo $\mathrm{dx}$, se o resultado dessa operação fosse maior que um, o df caminha mais que o dx, se o resultado for menor que menor que um, o dx caminha mais que o df.

A notícia se espalhou que nem fofoca, logo todos os pontos exibidos ganharam uma reta, e seus respectivos df e dx queriam saber quem andava mais em cada ponto. Mariana fez a divisão deles e com as respostas ela descobriu que tinha descoberto outra função, que ela representou por Mariana Linha. Assim, como toda história legal, eles viveram felizes para sempre.

Quando ela acabou de me contar a história, a primeira coisa que ela me perguntou foi:

Inópia: Aline, você vai dar o meu nome pra história? Eu contei a história certa?

Aline: Inópia, você pode colocar o nome da história de História da Derivada de Inópia. Você contou muito bem. Agora que você tem uma história com o teu nome, conta pras tuas amigas, assim como eu contei pra ti, se elas entenderem você pode dar o nome delas pra história.

Inópia: Posso contar pro professor Valmor²? (Professor de Matemática)

Aline: Claro; e não se esqueça de me contar os resultados.

Inópia: Aline, obrigada por me contar essa história, eu adorei. Obrigada por sempre me ajudar e me ensinar coisas novas e boas. Você é a melhor professora do mundo, te amo.

Nesse momento eu me senti muito feliz, realizada, por ter ensinado algo bom para uma pessoa que eu gosto muito, além de perceber que tudo está relacionado com o nosso interesse, com a nossa curiosidade.

Com a história da Derivada de Mariana, minha prima disse que entendeu que sempre que temos algo muito pequeno (infinitesimal), como o país do ponto, podemos dar zoom e ampliar a imagem, e, assim, podemos calcular coisas que, à primeira vista, são muito pequenas, mas que, com o zoom, tornam-se maiores.

Relatei a história, passo a passo, conforme aconteceu. O que está em itálico são os pontos principais da história. Foi o que mais chamou a atenção dela. É o resumo da história da Derivada de Mariana, como ela entendeu e foi anotando. E, bem no fim no parágrafo, está a ideia central, em poucas palavras, que ela gravou.

\footnotetext{
${ }^{2}$ Nome fictício.
} 
No dia seguinte liguei pra ela novamente, e perguntei se ela ainda se lembrava da história que eu havia contado. Ela me disse que sim. Então, eu perguntei assim:

Em poucas palavras, o que você entendeu com a história da Derivada de Mariana?

Ela me disse:

Com essa história eu aprendi que quando temos algo muito pequeno, podemos dar zoom pra ver melhor, porque foi isso que a Mariana mandou os dois habitantes que viviam no país do ponto e que viviam brigando fazerem, assim eles pararam de brigar e viveram felizes para sempre.

Depois que ela me disse isso, eu percebi que ela conseguiu gravar a história, e que certamente ela vai passá-la adiante e, assim, não vai esquecê-la.

Sugeri a ela que pegasse como exemplo as lajotas da calçada da sua casa, pois elas têm forma de quadrado, e no centro têm uma flor. Disse-lhe que podia imaginar o $d f$ e o $d x$ ali; ela conseguiu entender isso quando eu lhe disse para pensar que o centro da flor era o ponto exibido da história; disse-lhe para colocar uma régua de um canto ao outro do quadrado. E ela conseguiu enxergar ali o $d f$ e o $d x$ ampliados.

No Dia de Natal, liguei para minha amiga e falei com a Inópia. Perguntei novamente pela história e se o conceito da derivada está muito claro pra ela. Ela me contou que contou a história para o seu professor de matemática; eu perguntei pra ela se ele havia entendido, e ela me disse que sim. Logo entrei em contato com ele, conversamos um pouco e ele me disse: Estou muito orgulhoso de você, pois você ensinou para Inópia algo muito importante, e de uma maneira que ela conseguiu entender com apenas 12 anos. Parabéns!

Logo eu expliquei como tudo ocorreu, contei que o meu professor de matemática e geometria contou a História da Derivada de Mariana para uma menina chamada Mariana e, logo, apresentou essa história para a minha turma da faculdade, e deu a ideia de que contássemos para uma criança a história, e, aí, eu lembrei-me da Inópia. Ela entendeu a ideia central da história e, então, eu dei o nome dela pra história e disse que ela poderia contar para suas amigas e ela me perguntou se poderia contar pra você, e eu disse que sim.

O professor disse que se admirou mais ainda porque, até então, ela não tinha muito interesse pela matemática, mas que ela aprendeu muito bem a moral da história.

Quando o professor Baldino nos apresentou a História da Derivada de Mariana e nos contou que ele a contara para uma menina de 10 anos, então, eu 
pensei comigo: se Mariana, com 10 anos, entendeu, por que a filha de minha amiga, de 12, não iria entender? Assim, resolvi fazer um teste contando a história para ela.

Procurei desafiar a Inópia sim, principalmente na imaginação. Desafieia, também, propondo dar o nome dela para a história, e isso foi de grande importância, porque penso que foi o que mais a interessou, em primeiro plano, antes de conhecer a história.

\section{Considerações de Roberto Baldino sobre o contexto da experiência}

Em 2011 pretendo tornar a introduzir o conceito de derivada através desta história. Creio que ela fornece um referencial adequado à determinação do nível de compreensão do conceito em diferentes alunos de diferentes faixas etárias. Convido o(a) leitor(a) a contar a história para outras crianças e nos relatar o resultado<rrbaldino@terra.com.br>. É preciso prosseguir a pesquisa e determinar em que medida o conceito de derivada realmente aparecerá nos relatos dessas crianças ou se apenas a ideia do zoom foi retida. De todo modo, aqui fica o desafio aos adeptos da teoria dos limites para ensino de derivadas: consigam alguma maneira de apresentar esse conceito a crianças de 10-12 anos e comparemos os resultados.

A disputa entre limites e infinitésimos, tanto na produção quanto no ensino de matemática, vem de longa data. Embora em quase todos os anos que tenhamos um novo livro de cálculo no mercado, todos eles apresentam a mesma organização. Por exemplo, o mais recente que me chegou as mãos (LARSON, 2011) começa com funções e limites, seguidos de derivadas e aplicações, mais funções, depois integrais e aplicações, técnicas de integração, terminando com funções de duas variáveis. O conceito de derivada é invariavelmente apoiado no conceito de limite: passa-se ao limite da reta tangente, retendo o valor final do coeficiente angular, ou inclinação. A experiência me tem mostrado que esse é um caminho que se torna cada vez mais difícil para calouros provenientes do ensino médio brasileiro.

Já há vários anos temos procurado uma alternativa para a introdução do conceito de derivada pela via dos infinitésimos. (CABRAL; BALDINO, 2006; BALDINO; MILANI, 2002; MILANI, 2002; BALDINO, 2000). Tanto o conceito de infinitésimos quanto de limite estavam presentes na passagem do século 17 ao 18, nos trabalhos de Newton e Leibniz. Porém, com as críticas dos filósofos, especialmente as do bispo Berkeley, aos fundamentos do cálculo, o 
conceito de limite foi se tornando preponderante. Com os trabalhos de Cauchy, em meados do século 19, o conceito de limite tornou-se central. Entretanto, Cauchy não se opunha aos infinitésimos e os usava corretamente (BALDINO; TEIXEIRA; SAD, 2001).

Os infinitésimos foram ridicularizados pelos matemáticos, mas nas engenharias, na mecânica e na física, continuaram a ser usados sem restrição. A matemática divorciou-se das demais ciências, com enormes prejuízos ao ensino. Hoje, um curso de cálculo que não introduza infinitésimos, nem mesmo por baixo do pano, como concepção clandestina, torna-se inútil para qualquer curso de engenharia. Formular problemas de cálculo integral por via de somas de Riemann torna-se muito difícil.

Movidos por essas considerações, Tânia Cabral e eu temos procurado desenvolver nossos cursos de cálculo, baseando-nos no conceito de diferencial, apresentado como a variação da função quando a variável sofre uma variação infinitesimal. Essa ideia é facilmente apresentada em menos de um minuto, em cada um dos dez ou quinze grupos em que dividimos nossas salas de aula. Aos alunos com curiosidade sobre o conceito de limite, recomendo a leitura do livro texto. As diferenças das funções compostas são apresentadas desde as primeiras semanas de aula, através de uma tabela de regras de diferenciação, a FT20, assim chamada porque, na primeira vez em que foi introduzida, era a ficha de trabalho número 20.

Em 2010/2 procedi assim. Do ponto de vista epistemológico, ou seja, da organização dos conhecimentos matemáticos, a ordem preconizada pelo livro texto (STEWART, 2010) seria: conceito (de derivada), cálculo (regras de derivação), aplicações (taxas relacionadas e otimização). Porém, do ponto de vista didático, ou seja, da sequiência de apresentação de conteúdos, há autonomia relativa dessa ordem. Junto com Tânia Cabral, eu já tinha feito tentativas de alterá-la e, em 2010/2 segui a ordem: cálculos - aplicações - conceito. Nas seis primeiras aulas (100 minutos cada uma) fizemos uma introdução, através de exercícios, do conceito de função. Na terceira semana começamos o cálculo de diferenciais de funções que se obtêm por composição e inversão das três funções elementares, polinômios, seno e exponencial. Eles aprenderam a regra da cadeia.

Com o conceito e cálculo das diferenciais tornou-se mais fácil abordar problemas de taxas relacionadas, mesmo antes da introdução formal do conceito de derivada; as taxas são o resultado da divisão de dois infinitésimos, dizemos. Por exemplo, para achar a velocidade, basta dividir o deslocamento infinitesimal 
$d x$ pela variação do tempo $d t$. Só no último bimestre de Matemática I introduzi o conceito de derivada como coeficiente angular da reta tangente, e passei aos problemas de relacionar crescimento de funções com sinais de suas derivadas

Portanto, introduzi o conceito de diferencial antes do conceito de derivada, mas não fiz exposições sobre a regra da cadeia na terceira semana de aula, como poderia parecer. A diferencial é uma decorrência natural do enfoque infinitesimalista. Porém, raramente vou ao quadro, a não ser ao final da aula, por no máximo cinco ou dez minutos. Manter cada aluno desafiado exclui aulas expositivas. O lema de ouro da pedagogia é: ensina-se ouvindo, aprende-se falando. Eu organizo a sala em grupos de 4, e trabalhamos segundo as regras da pedagogia da Assimilação Solidária (BALDINO, 1998). Eu vou de grupo em grupo, atendendo aos chamados e fornecendo a cada um a explicação adequada no momento em que surge a dúvida. A tarefa é de aprendizagem, introduzida por uma ficha de trabalho (FT) distribuída a cada aluno. Cada grupo recebe uma folha de tarefa sobre a qual nos comunicamos e onde eles devem anotar os nomes dos participantes. No início da terceira semana, eles receberam a FT20, a ficha que venho usando há vários anos com as regras de diferenciação em forma simbólica de um lado e em Português corrente do outro. Por exemplo, de um lado está escrito: a diferencial do seno de uma variável é... o cosseno da variável vezes a diferencial da variável". Virando a folha, lê-se: Os alunos são instados a não preencherem as reticências com letras, exatamente para poderem considerar qualquer função no lugar delas. Segundo a FT20, para calcular diferenciais, basta saber ler. Eu insisto para que eles enunciem as regras em voz alta, à medida que as aplicam, como se estivessem decorando a fala de uma representação teatral: aprender encenando.

Poder-se-ia perguntar se os alunos aceitam calcular sem ter o conceito do que estão calculando. De fato, em alguns grupos surgiu a pergunta: o que é isto que estamos calculando?. Em menos de um minuto, desenhei na folha de tarefa o gráfico de uma função e expliquei o significado da diferencial: é esta variação aqui, de $f(x)$ quando a variável $x$ sofre um acréscimo infinitesimal. É importante observar que isso bastou, satisfez a curiosidade e os alunos prosseguiram o cálculo das diferenciais. Não houve, por parte deles, qualquer preocupação em justificar previamente o cálculo que estavam a aprender. Aos que estranharam o termo infinitésimo respondi, en passant: é uma grandeza muito, muito pequena. Apenas um aluno, algumas aulas depois, comparando com o que colegas da UFRGS estavam estudando, perguntou o que era a derivada e como se calculava. $O$ desenvolvimento da derivada de $f(x)=x^{2}$ seguido da 
garantia de que todas as demais regras da FT20 eram provadas assim, o satisfez plenamente. Mais adiante, apresentei esse cálculo para a turma toda, no final de uma aula, mas o sentido dele não precisou vir antes.

Como segui a ordem cálculos - aplicações - conceito, enfrentei o problema de trabalhar taxas relacionadas e problemas de otimização sem passar pelo o conceito de derivada. Nos problemas de taxas relacionadas, a vantagem da estratégia do cálculo antecipado de diferenciais se manifestou plenamente. Por exemplo, no problema do cálculo da taxa de aumento da área de um retângulo, cada um de cujos lados está aumentado a uma certa taxa, eles não tiveram dúvidas em, uma vez expressa a área $\mathrm{A}(\mathrm{x}, \mathrm{y})$ = xy como função de duas variáveis, imediatamente calcular a diferencial pela FT20: $d A(x, y)=x d y+y d x$. Não tínhamos ainda introduzido a FT sobre velocidade, no entanto a maioria não teve dificuldade em entender os $8 \mathrm{~cm} / \mathrm{s}$ que o livro dava como taxa de aumento de um dos lados, significavam $\frac{d x}{d t}$. Logo acataram a sugestão de dividir tudo por $d t$. Acharam fácil. O mesmo exercício pela via de derivadas é bem mais difícil. Nos problemas de otimização, um desenho os convenceu de que, nos pontos de máximo ou mínimo (certamente interiores!) a diferencial não pode ser positiva nem negativa, portanto é zero. Ninguém sugeriu que poderia ser infinitesimal, portanto esse problema não foi abordado.

Encerrei o curso com o conceito de derivada. Eles sabiam que se calculava a derivada multiplicando a diferencial por $d x$, mas não tinham sido expostos ao conceito de derivada como coeficiente angular da reta tangente. Logo após a segunda prova, distribuí duas fichas de trabalho, uma sobre velocidade, que já tinha usado em anos anteriores, e outra mais dirigida, sobre derivada e coeficiente angular da reta tangente. Essas fichas de trabalho fracassaram: um número muito grande de alunos não relacionava distância, tempo e velocidade. O substrato de experiência física que serviria de base se transformou em problema. Que novidade deveria ser pensada? No fim de semana prolongado, durante a festa de aniversário de um amigo, puxei para um canto Mariana ${ }^{3}$, a neta de 9 anos de meu vizinho, e lhe contei aquilo que veio a ser a primeira versão da História da Derivada. Para meu espanto, ela não só gostou como se apressou em contá-la à professora, Tânia, o que fez com exatidão. Elaborei, então, a versão da FT que foi distribuída aos alunos na aula seguinte. Pedi que lessem a história com atenção e, em seguida, apresentei um teste escrito em

${ }^{3}$ Mariana Leão da Cruz (divulgação autorizada). 
que deveriam traçar o gráfico da derivada de uma função, calculando os coeficientes angulares de retas tangentes em vários pontos do gráfico. Distribuí réguas e esquadros. Durante o teste, o encaminhamento foi: se estão com dúvidas é porque não entenderam a história; releiam-na. Recolhido o teste, eles o retrabalharam em grupo.

O resultado do teste não é muito representativo, porque eles tiveram alguma ajuda durante o mesmo. Porém, não tiveram facilidade. Como eu tinha escrito a fórmula da função ao lado do gráfico, muitos desenharam o gráfico pela fórmula da função derivada, e não pelo traçado das tangentes. Contudo, na terceira prova pedi uma questão específica. Dos 27 que fizeram a prova, o resultado dessa questão foi: média 4,1 (em 10) e desvio padrão 4,6. Ou seja, apesar de todas as provas serem feitas com consulta livre à bibliografia e notas de aula, a turma se dividiu: metade entendeu e soube executar o processo; outra metade, aparentemente não entendeu. É preciso continuar os testes.

Convidamos o leitor.

\section{Considerações finais}

Quando este artigo estava em fase de acabamento consultamos os pais de Mariana e de Inópia, pedindo autorização para divulgar os nomes de suas filhas. Os pais de Mariana prontamente concordaram, mas os de Inópia, não. Tivemos de mudar o nome e detalhes que pudessem levar a identificação. Eis como eles reagiram, segundo relato de Aline.

Liguei pra eles, falei com minha amiga e com o marido dela... mas tudo em vão. Minha amiga alega que não quer o nome da filha dela nessas coisas de que ela não tem conhecimento. Expliquei a ela, e perguntei se não confiava em mim. Ela me disse, antes, quando eu morava lá, até que ela confiava, mas agora, depois de eu morar há quase um ano na Grande Porto Alegre, sinceramente, não. Tentei argumentar de todas as maneiras, mas eles deixaram bem claro que não aceitam que o nome da Inópia seja envolvido nessa história.

\section{Referências}

BALDINO, R. R. Assimilação Solidária: escola, mais-valia e consciência cínica.

Educação em Foco, Juiz de Fora, v. 3, n. 1, p. 39-65, jun. 1998. 
BALDINO, R. R. Infinitésimos: quem ri por último? Boletim do GEPEM, Rio de Janeiro, v. 36, p. 69 - 82. fev. 2000.

BALDINO, R. R.; TEIXEIRA, M. V.; SAD, L. A. Cauchy and the problem of point-wise convergence. Archives Internationales D'histoire Des Sciences, Liège, Bélgica, v. 51, n. 147, p. 277 - 308, 2001.

BALDINO, R. R.; MILANI, R. The theory of limits as an obstacle to infinitesimal analysis. In: Proceedings of the $26^{\text {th }}$ Annual Conference of the International Group for the Psychology of Mathematics Education, PME, 26 ${ }^{\text {th }}, 2002$, Norwich. Proceedings... Norwich: University of East Anglia, 2002, v. 3, p. 345 - 352.

CABRAL, T. C. B.; BALDINO, R. R. Cálculo infinitesimal para um curso de engenharia. Revista de Ensino de Engenharia, Brasília, v. 25, no. 1, jan./jun. p. 3 - 16, 2006.

LARSON, R. Cálculo aplicado: curso rápido. São Paulo: Cengage Learning, 2011.

MILANI, R. Concepções infinitesimais em um curso de cálculo. 2002, $127 \mathrm{f}$.

Dissertação (Mestrado em Educação Matemática) - Instituto de Geociências e Ciências Exatas, Universidade Estadual Paulista, Rio Claro, 2002.

STEWART, J. Cálculo. 6. ed. São Paulo: Cengage Learning, 2010, 63p.

Submetido em Março de 2011. Aprovado em Junho de 2011. 
